\title{
Tityus serrulatus scorpion venom improves survival and lung inflammation in lethal sepsis induced by CLP in mice
}

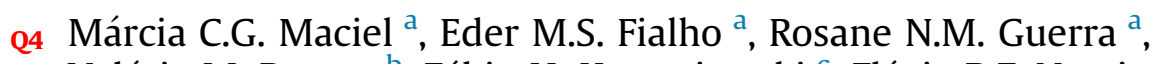
Valéria M. Borges ${ }^{\mathrm{b}}$, Fábio H. Kwasniewski ${ }^{\mathrm{c}}$, Flávia R.F. Nascimento ${ }^{\mathrm{a},}$

a Laboratório de Imunofisiologia, Departamento de Patologia, Centro de Ciências Biológicas e da Saúde,

Universidade Federal do Maranhão, São Luís, MA, Brazil

${ }^{\mathrm{b}}$ FIOCRUZ, Centro de Pesquisas Gonçalo Moniz, Salvador, BA, Brazil

${ }^{\mathrm{c}}$ Laboratório de Imunofarmacologia, Departamento de Ciências Patológicas, Centro de Ciências Biológicas,

Universidade Estadual de Londrina, Londrina, PR, Brazil

\section{A R T I C L E I N F O}

\section{Article history:}

Received 6 March 2014

Received in revised form 11 June 2014

Accepted 19 June 2014

Available online xxxx

\section{Keywords:}

Tityus serrulatus

Venom

CLP

Sepsis

Inflammation

Cytokines

\begin{abstract}
A B S T R A C T
Tityus serrulatus venom (Tsv) modifies the behavior of immune cells and induces the production of inflammatory and anti-inflammatory cytokines; such action may interfere with physiological or pathological states. Because sepsis is characterized as an inflammatory disorder, the aim of present study was to investigate the effect of a non-lethal dose of Tsv in mice submitted to a polymicrobial infection by cecal ligation and puncture (CLP) model. The parameters evaluated were survival index, cellularity on lymphoid organs, peritoneal cavity and brochoalveolar space, production of IL-10, IL-12, IL-6, TNF- $\alpha$, IFN- $\gamma$ and MCP-1, pulmonary inflammation and oxidative burst. The results demonstrated that in sharp contrast to CLP group in which sepsis was lethal in a $24 \mathrm{~h}$ period all mice pretreated with Tsv survived even $60 \mathrm{~h}$ after CLP. Lung inflammation, another hallmark of CLP group, was also dramatically down regulated in Tsv/CLP group. Despite pretreatment with Tsv did not reduce the inflammatory serum cytokines when compared to CLP group; there was an increase in IL-10. In conclusion, subcutaneous Tsv administration 6 h before CLP was able to control the harmful effects of sepsis (lethality and lung inflammation). We suggest that both systemic IL-10 and oxidative burst are involved in this effect.
\end{abstract}

(c) 2014 Published by Elsevier Ltd.

\section{Introduction}

Sepsis is a complex clinical syndrome that results from the host response to an infectious process, which leads to an exacerbated inflammatory response. The condition can progress to disseminated intravascular coagulation, acute respiratory distress syndrome, multiple organ failure, and death. Severe sepsis and septic shock represent major causes of morbidity and mortality and affect more than

\footnotetext{
* Corresponding author. Campus do Bacanga, Prédio do Integrado, CCBS, Bloco 1, Laboratório de Imunofisiologia. Av dos Portugueses s/n, Bacanga, São Luís, MA, CEP 65085-580, Brazil. Tel.: +55 9832728548.

E-mail address: nascimentofrf@yahoo.com.br (F.R.F. Nascimento).
}

750,000 people per year in the United States of America, with an annual mortality of approximately 220,000 (Angus et al., 2001). In Brazil, sepsis was suggested as a major public health problem in intensive care units, with an incidence density of approximately 57 per 1000 patientdays and with mortality rates as high as 50\% (Silva et al., 2004). Although sepsis is a well-studied condition in different animal models, it remains very difficult to manage and treat in humans, opening the possibility of studying alternative ways to improve the host response to sepsis or treatment.

Some natural products exert a positive impact on the survival index of mice subjected to a cecal ligation and puncture (CLP) model of polymicrobial sepsis (Wang et al., 
2006; Maciel et al., 2008; Yang et al., 2009). Previous studies revealed the important effects of some venoms on experimental sepsis (Frolkis et al., 2010). In addition, venom from Tityus spp. scorpions increases the number of neutrophils in the blood (Fialho et al., 2011) as well as activates these cells (Borges et al., 2011). Because neutrophils play an important role in the clearance of bacterial infection, it is reasonable to propose that the venom from Tityus scorpions may improve the organic dysfunction that occurs during sepsis.

Tityus serrulatus venom (Tsv) can cause local and systemic inflammation and the generation of soluble mediators with a vast array of effects (Pessini et al., 2003; Severino et al., 2009). Despite deleterious effects, Tsv has immune modulatory properties that could be useful for pathological states in which the modulation of the immune system is an important goal. Studies of the effects of Tsv or its toxins on the immune system have demonstrated that this venom increases the in vitro production of reactive oxygen species and cytokines, such as tumor necrosis factor- $\alpha$ (TNF- $\alpha$ ), interferon- $\gamma$ (IFN- $\gamma$ ) and interleukin-6 (IL-6), by murine macrophages (Petricevich, 2002; Zoccal et al., 2011). Systemic IL-6, IL- $1 \alpha$ and TNF- $\alpha$ were also detected in patients who experienced moderate to severe accidents up to 24 h later (Fukuhara et al., 2003). In fact, some of the consequences of human and experimental envenomation are associated with the secretion of soluble mediators by immune cells (Petricevich, 2010).

In view of the immune-modulatory effects of Tsv and the success achieved in previous studies, we assessed the effect of Tsv on sepsis induced by CLP. The CLP model was chosen because after the perforation of the intestinal wall, a subsequent and gradual release of fecal material into the peritoneal cavity induces peritonitis, which can progress to sepsis and septic shock, reproducing the physiopathology of polymicrobial sepsis in humans that is caused by bowel perforation, colitis, or postoperative peritonitis (Garrido et al., 2004).

\section{Material and Methods}

\subsection{Venom}

The lyophilized crude $T$. serrulatus scorpion venom (Tsv) was obtained from the Arthropod Laboratory of Instituto Butantan. The venom was stored at $-20^{\circ} \mathrm{C}$ until the time of use, when it was diluted in sterile phosphate-buffered saline (PBS).

\subsection{Animals}

Swiss male mice (2-3 months, 20-25 g) were obtained from the Central Animal House of Universidade Federal de Maranhão (UFMA) and kept at the animal house of the Laboratory of Immunophysiology in a controlled environment under a 12/12-h light/dark cycle. Water and food were available ad libitum until the day of sacrifice. The animals were handled according to the guidelines of the Brazilian Society for Laboratory Animal Science (SBCAL) and the Ethics Committee of UFMA (protocol No. 006438/ 2008-68) approved the study.

\subsection{Experimental design}

The mice were shared in four groups. The first group (PBS group, $n=5$ ) received only sterile PBS, the second (Tsv group, $n=5)$ received a non-lethal dose of Tsv $(200 \mu \mathrm{g} / \mathrm{kg})$, the third (CLP group, $n=10$ ) received PBS and 6 h later it was induced the CLP and the fourth (CLP + Tsv group, $n=10)$ received a non-lethal dose of Tsv $(200 \mu \mathrm{g} / \mathrm{kg})$ and 6 h later it was induced the CLP. The non-lethal dose was chosen according to Pessini et al. (2003). All the treatments were done by subcutaneous (sc.) route. Polymicrobial sepsis was induced using CLP method according to previously described (Benjamim et al., 2000). Briefly, under deep anesthesia, a laparotomy was performed and the cecum was mobilized and ligated below the cecal valve, punctured $10 \times$ with an 18-gauge needle to induce the lethal sepsis. The cecum was replaced into peritoneal cavity and the abdomen was closed in two layers. Saline $(0.5 \mathrm{~mL} / 10 \mathrm{~g}$ body weight) was given subcutaneously to CLP animals for fluid resuscitation. After $12 \mathrm{~h}$ of CLP a half of the animals was sacrificed with an overdose of the anesthetic $(150 \mathrm{mg} / \mathrm{kg}$ ketamine hydrochloride and $120 \mathrm{mg} / \mathrm{kg}$ xylazine hydrochloride) to perform the assays. Another half of the animals were maintained alive to evaluate the lifespan. The mortality of the animals was recorded every $12 \mathrm{~h}$ until the 5th day (Maciel et al., 2008).

\subsection{Isolation of peritoneal cells}

The peritoneal cavity of the animals was washed with $5 \mathrm{~mL}$ sterile PBS. Cell suspensions were aspirated with a syringe and needle and transferred to conical propylene tubes. The tubes were kept on ice $\left(4^{\circ} \mathrm{C}\right)$ until the assays.

\subsection{Bronchoalveolar lavage (BAL) and histopathologic analyses}

The trachea was exposed and intubated using catheter and was instilled with $1 \mathrm{~mL}$ of cold PBS. The total number of BAL cells was determined as described bellow. Thereafter, the lungs were collected, weighed, and fixed in $10 \%$ formalin for histology. The histological analysis evaluated the following parameters: vascular congestion, hemorrhage and cellular infiltration, according the following scores: 0-absent, 1-weak, 2-moderate, 3-strong. Histological evaluation was performed randomly and blindly.

\subsection{Total and differential count of blood, peritoneal and bronchoalveolar cells}

For total peritoneal cell determination, nine volumes of the cellular suspension were added to 1 volume of $0.05 \%$ crystal violet dissolved in $30 \%$ acetic acid and the cells were counted using a bright-line Neubauer chamber (Sigma) under a common light microscopy at $400 \times$ magnification. Differential cell counts were determined using the cytospin system (800 rpm/3 min), fixed, and stained with the Instant-Prov kit (Newprov, Pinhais, Brazil). The percentage of cell subpopulations was calculated based on the count of 100 cells and transformed in absolute number based on the total counting. Blood smears were prepared and stained 
with the Instant-Prov kit (Newprov, Pinhais, Brazil). The slides were examined under a common light microscopy at $1000 \times$ magnification. The percentage of cell subpopulations was calculated based on the count of 100 cells.

\subsection{Lymph node, spleen and bone marrow's cells counting}

After sacrifice, the femur, spleen and inguinal lymph node were removed. The femur was perfused with $1 \mathrm{~mL}$ of PBS for the isolation of bone marrow cells. The spleen was removed, triturated with $5 \mathrm{~mL}$ PBS and passed through a silk sieve. The inguinal lymph node was removed and triturated with $1 \mathrm{~mL}$ RPMI medium supplemented with Lglutamine and $10 \%$ fetal bovine serum. Nine volumes of the cellular suspension were added to 1 volume of $0.05 \%$ crystal violet dissolved in 30\% acetic acid and the cells were counted using a bright-line Neubauer chamber (Sigma) under a common light microscopy at $400 \times$ magnification.

\subsection{Quantification of cytokines by the CBA technique}

The cytometric bead array (CBA) technique was used for the quantification of IL-12, MCP-1, IL-6, IL-10, TNF- $\alpha$, and IFN$\gamma$. The mouse inflammatory cytokine kit was obtained from Becton Dickinson Biosciences (San Jose, CA, USA). Serum or bronchoalveolar lavage (BAL) samples obtained $12 \mathrm{~h}$ after the CLP, were centrifuged at $1500 \mathrm{rpm}$ for $10 \mathrm{~min}$ at room temperature for the precipitation of debris. Next, $25 \mu \mathrm{L}$ of the standard, provided by the manufacturer, or the samples to be tested was mixed with the detection reagent from the kit. The samples were incubated $2 \mathrm{~h}$ at room temperature, protected from light. After, the samples were suspended in $500 \mu \mathrm{L}$ of wash buffer to each assay tube and centrifuge at $200 \mathrm{~g}$ for $5 \mathrm{~min}$. The samples were suspended in $150 \mu \mathrm{L}$ of wash buffer to each assay tube and read in a FACSCalibur flow cytometer (Becton Dickinson). The cytometer was calibrated using three samples of setup beads previously incubated with FITC or PE, or without any developing reagent according to manufacturer instructions. After reading of the standards and samples, the data were analyzed with the BD CBA Isotype Analysis software (Becton Dickinson). The results are expressed as $\mathrm{pg} / \mathrm{mL}$ for each cytokine.

\subsection{Hydrogen peroxide assay}

To evaluate $\mathrm{H}_{2} \mathrm{O}_{2}$ release, a horseradish peroxidasedependent phenol red oxidation micro assay was used (Pick and Mizel, 1981; Pick and Keisari, 1980). In this assay two million peritoneal cells were suspended in $1 \mathrm{~mL}$ freshly prepared phenol red solution that consisted of ice-cold Dulbecco's PBS containing $5.5 \mathrm{mM}$ dextrose, $0.56 \mathrm{mM}$ phenol red (Sigma) and $8.5 \mathrm{U} / \mathrm{mL}$ horseradish peroxidase type II (Sigma). One hundred microliters of the cell suspension were added to each well, and incubated in the presence or not of $10 \mathrm{ng}$ phorbol myristate acetate (PMA) (Sigma), for $1 \mathrm{~h}$ at $37^{\circ} \mathrm{C}$ in a humid atmosphere containing $5 \% \mathrm{CO}_{2}$ and $95 \%$ air. The plates were centrifuged once at $150 \times \mathrm{g}$ for $3 \mathrm{~min}$ and the supernatants were collected and transferred to another plate. The reaction was stopped with $10 \mu \mathrm{L} 1 \mathrm{~N} \mathrm{NaOH}$. The absorbance was measured at $620 \mathrm{~nm}$ with a micro plate reader (MR 5000, Dynatech Laboratories
Inc., Gainesville, VA, USA). Conversion of absorbance to $\mu \mathrm{M}$ $\mathrm{H}_{2} \mathrm{O}_{2}$ was done by comparison to a standard curve obtained with known concentrations of $\mathrm{H}_{2} \mathrm{O}_{2}(5-40 \mu \mathrm{M})$.

\subsection{Statistical analysis}

Results were expressed as the mean \pm standard deviation. Statistical analysis was performed using the $t$ test or analysis of variance (ANOVA) followed by multiple comparison test (Newman-Keuls) using the Graph Pad Prism software, version 5.0. The differences were considered to be significant when $p \leq 0.05$. Mice lifespan was demonstrated using the Kaplan-Meier curve and the log-rank statistical test was applied to compare the curves. All experiments were repeated for at least two times.

\section{Results}

\subsection{Effect of pretreatment with Tsv on the lethality induced by CLP}

The sepsis induced by CLP was lethal to $100 \%$ of the animals $24 \mathrm{~h}$ after CLP. In sharp contrast, $100 \%$ of the animals pretreated with Tsv 6 h before CLP were still alive 5 days after CLP.

\subsection{Effect of pretreatment with Tsv on pulmonary inflammation}

CLP induced pulmonary inflammation with cellular infiltration, vascular congestion and hemorrhage. Vascular congestion and hemorrhage were not present in the group pretreated with Tsv (Table 1), but cellular infiltration, which was identified via histological analysis of the lungs (Table 1 and Fig. 1A, B) and the evaluation of cells recovered by bronchoalveolar lavage (BAL), were present in reduced numbers (Fig. 1C). The envenomation per se did not alter the number of cells in the BAL (PBS group, $14 \pm 6 \times 10^{4}$ cells $/ \mathrm{mL} v s$. Tsv group, $10 \pm 6 \times 10^{4}$ cells $\left./ \mathrm{mL}\right)$. It is important to emphasize that the CLP + Tsv group exhibited the same number of cells in the BAL as the nonseptic mice.

\subsection{Production of cytokines}

Cytokine production was analyzed both systemically (i.e., in the blood) (Table 2) and in the lungs (i.e., in the BAL)

\section{Table 1}

Evaluation of pulmonary inflammation. The mice were injected subcutaneously with PBS (CLP) or Tsv ( $200 \mu \mathrm{g} / \mathrm{kg})$ and submitted to CLP 6 h later. The lungs were removed and fixed in $10 \%$ formalin $12 \mathrm{~h}$ after CLP. The lung histology of either the CLP (A) or the Tsv group (B) was evaluated at $400 \times$ magnification.

\begin{tabular}{lll}
\hline & CLP & CLP + Tsv \\
\hline Hemorrhage & $2.3 \pm 0.5^{\mathrm{a}}$ & $0.0 \pm 0.0^{*}$ \\
Vascular congestion & $3.0 \pm 0.0$ & $0.0 \pm 0.0^{*}$ \\
Cell Infiltration & $2.3 \pm 0.5$ & $1.0 \pm 0.0^{*}$ \\
\hline
\end{tabular}

$N=5$ animals per group. ${ }^{*} p<0.05$ when compared to control.

a The results are expressed as the means \pm SD from the scores: 0 -absent, 1-weak, 2-moderate, 3-strong. 


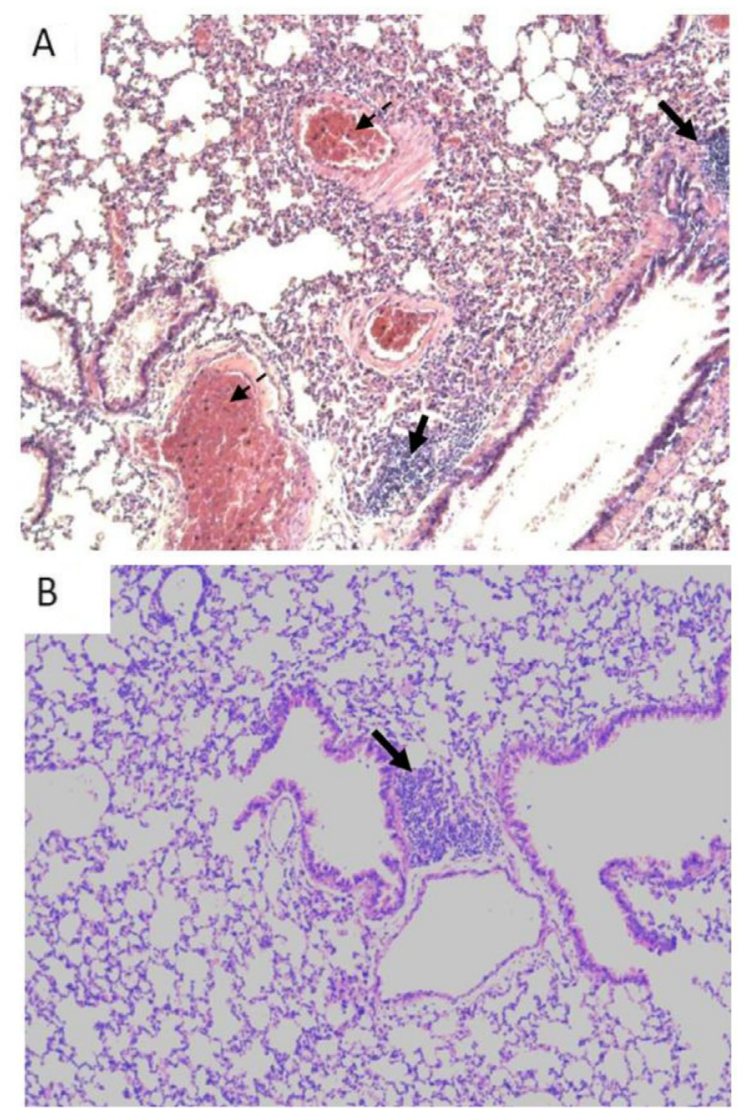

C

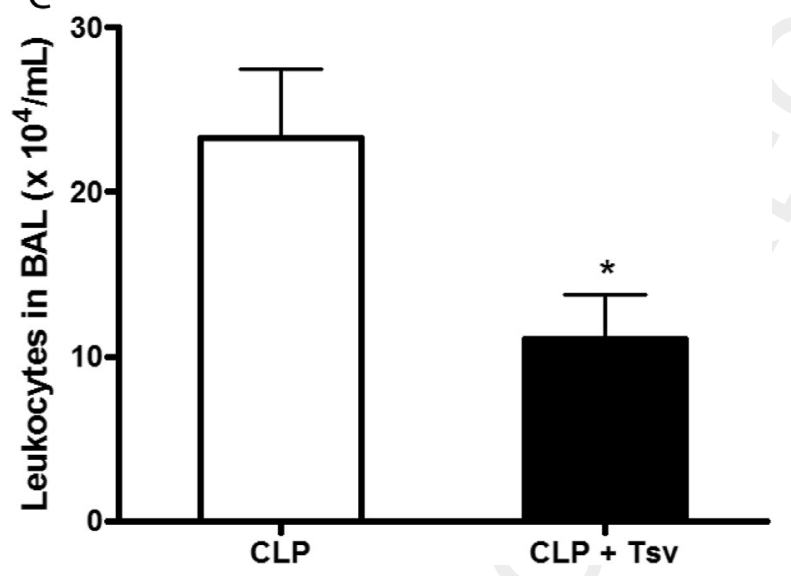

Fig. 1. Pulmonary inflammation in septic mice treated with Tityus serrulatus venom (Tsv). The mice were injected subcutaneously with PBS (CLP) or Tsv $(200 \mu \mathrm{g} / \mathrm{kg}$ ) and submitted to CLP $6 \mathrm{~h}$ later. The BAL fluid was collected $12 \mathrm{~h}$ after CLP, and the lungs were removed and fixed in $10 \%$ formalin. The lung histology of either the CLP (A) or the Tsv group (B) was evaluated at $400 \times$ magnification. The number of leucocytes in the BAL fluid was quantified (C). The results are expressed as the means \pm SD of 5 animals per group. ${ }^{*} p<0.05$ compared to CLP.

(Table 3). In the animals that were not subjected to CLP (i.e., the PBS group), Tsv (i.e., the Tsv group) did not induce systemic or pulmonary production of any cytokines, with the exception of systemic IL-10. In the animals subjected to
CLP, increased systemic production levels of TNF- $\alpha$, IFN- $\gamma$, MCP-1, IL-6 and IL-10 were observed, but only MCP-1 and IL-6 were elevated in the lungs. Pretreatment with Tsv (i.e., the CLP + Tsv group) did not modify the cytokine profile in septic animals, even compared to the Tsv group in nonseptic mice, with the exception of the large amount of systemic IL-10.

\subsection{Effect of pretreatment with Tsv on inflammatory cell recruitment}

The envenomation did not induce alterations in the total or differential cell counts in the peritoneal cavity per se. The CLP induced an increase of the total cell number in the peritoneal cavity that was not altered by Tsv pretreatment. However, the differential cell counts in the CLP + Tsv group revealed an increased number of macrophages and a reduced number of neutrophils when compared to the PBS group (Table 4).

\subsection{Hematological alterations}

Prophylactic treatment with Tsv reversed the percent increase in the number of neutrophils that was induced by sepsis. However, mice pretreated with the venom presented increases in the percentages of lymphocytes and monocytes when compared to the control group (Fig. 2).

\subsection{Effects of pretreatment with Tsv on lymphoid organs}

The envenomation did not induce alterations in the bone marrow and spleen cell numbers, but the treatment induced a decrease in the lymph node cell number. Pretreatment with Tsv reduced the numbers of bone marrow, lymph node and spleen cells when compared to the CLP group (Table 5).

\subsection{Effect of pretreatment with Tsv on the peritoneal cell activation induced by CLP}

Pretreatment with Tsv significantly increased ex vivo hydrogen peroxide release by peritoneal cells when compared to the control group. The venom increased the ex vivo spontaneous and PMA-stimulated $\mathrm{H}_{2} \mathrm{O}_{2}$ released by peritoneal cells (Fig. 3). No $\mathrm{H}_{2} \mathrm{O}_{2}$ secretion was induced by Tsv in non-septic mice.

\section{Discussion}

This study demonstrated the protective effects of the subcutaneous administration of Tsv on CLP-induced sepsis. Tsv injected $6 \mathrm{~h}$ prior to CLP protected the animals against lung inflammation and death caused by sepsis.

Sepsis is recognized as one cause of lung injury, and in this study, an indirect insult on the lungs was likely achieved. The observed signs of lung inflammation were caused by cytokines or other mediators released into blood as a result of peritonitis; the main target of these mediators is represented by pulmonary endothelial cells (Rocco and Pelosi, 2008). Thus, the vascular congestion, hemorrhage and cellular infiltration found in the lungs of septic animals 
Table 2

Cytokine levels in the serum of non-septic or septic mice treated with Tityus serrulatus venom (Tsv). Mice were injected subcutaneously with PBS or Tsv $(200 \mu \mathrm{g} / \mathrm{kg})$. A half of the animals in each group were subjected to CLP $6 \mathrm{~h}$ later (CLP and CLP + Tsv). The blood was collected $18 \mathrm{~h}$ after the Tsv injection (i.e. QQ2 $12 \mathrm{~h}$ after the CLP). The cytokines levels were performed in the serum using CBA assay.

\begin{tabular}{llll}
\hline & PBS & Tsv & CLP \\
\hline MCP-1 & $96.7 \pm 5.8$ & $93.3 \pm 15.3$ & $30,493.0 \pm 24,703.0$ \\
IL-12 & $44.3 \pm 11.7$ & $42.9 \pm 12.4$ & $50.0 \pm 10.1$ \\
IL- 6 & $28.2 \pm 20.8$ & $17.6 \pm 7.9$ & $1099.0 \pm 2822.0$ \\
TNF- $\alpha$ & $31.3 \pm 6.4$ & $34.7 \pm 5.8$ & $321.1 \pm 130.6$ \\
IFN- $\gamma$ & $4.3 \pm 0.4$ & $5.0 \pm 1.2$ & $8.2 \pm 1.6$ \\
IL-10 & $87.9 \pm 4.7$ & $111.7 \pm 10.1^{\#}$ & $269.7 \pm 109.6$ \\
\hline
\end{tabular}

a means \pm S.D. of 5 animals per group $(\mathrm{pg} / \mathrm{mL})$.

${ }^{\#} p<0.05$ when compared to PBS group. ${ }^{*} p<0.05$ when compared to CLP group. without Tsv pretreatment might have been caused by inflammatory cytokines (i.e., TNF- $\alpha$, IL-6 and MCP-1) that were released into the blood and that then acted on lung vessels and endothelial cells. During sepsis, proinflammatory cytokines, such as IL-6, TNF- $\alpha$, IL-12, MCP-1, among others, are up-regulated and play roles in the complex network of interactions associated with sepsis inflammatory cytokines are involved in the dysfunctions observed during sepsis, we first investigated the production of selected cytokines (i.e., IL-6, IL-12, TNF- $\alpha$, IL-10 and MCP-1) under those conditions and the effects of Tsv pretreatment on cytokine production.

Here, pretreatment with Tsv failed to modify the levels of inflammatory cytokines found in the blood $12 \mathrm{~h}$ after CLP but increased the level of IL-10 found in the sera from septic animals. This increase was detected in non-septic mice receiving Tsv and in greater amounts in the septic group pretreated with Tsv. This overproduction of IL-10 that was induced by Tsv in septic mice likely protected the animals against sepsis lethality and lung inflammation. We previously demonstrated that Tsv administration via the subcutaneous route promotes systemic alterations in cellular mobilization and cytokine secretion. In fact, inflammatory and anti-inflammatory cytokines are also produced during human moderate to severe envenomation (Fukuhara et al., 2003) and in experimental models of envenomation using Tsv (Petricevichi and Peña, 2002; Pessini et al., 2003).

Despite the rapid production of inflammatory cytokines (i.e., TNF- $\alpha$ and IL- 6 were produced 30 and 120 min after Tsv administration, respectively), significant production of the inflammatory cytokine IL-10 occurred $6 \mathrm{~h}$ after Tsv (Cavaillon et al., 2003). Because inflammatory and anti- administration (Fialho et al., 2011). This time corresponded with the time at which we induced the CLP in the mice; thus, the milieu was primarily and persistently antiinflammatory. This effect could explain the observed reduction of lung inflammation and the improvement in survival.

IL-10 has also been detected after human envenomation (Fukuhara et al., 2003) and in models of moderate to severe envenomation with T. serrulatus (Petricevichi and Peña, 2002), Centruroides noxius and Androctonus australis hector venoms (Petricevich, 2006; Adi-Bessalem et al., 2008), which are all scorpions from the Buthidae family. IL-10 is a mediator that is released as a part of a regulatory mechanism that limits collateral damage when an immune response is established (Moore et al., 2001). Our results are consistent with those reported for experimental endotoxemia (Gérard et al., 1993) and CLP-induced sepsis (Van Der Poll et al., 1995), in which IL-10 production was related to protection against lethality.

Peptides with antimicrobial activity can be detected in venoms from African scorpions, as described previously (Conde et al., 2000; Corzo et al., 2001; Moerman et al., 2002). In the Tityus genus, one report demonstrated that antibacterial peptides isolated from Tityus discrepans exhibited activity against Gram-positive and Gramnegative bacteria (Díaz et al., 2009). However, working with crude venoms from $T$. serrulatus and Tityus bahiensis, another group found no activity against the Gram-positive bacterium Staphylococcus aureus (Ciscotto et al., 2009). The bactericidal activity of crude venom is possible and was described in a recent study that used venom isolated from Heterometrus xanthopus (Ahmed et al., 2012). In our in vivo
Cytokine levels in the bronchoalveolar lavage from nonseptic or septic mice treated with Tityus serrulatus venom (Tsv). Mice were injected subcutaneously with PBS or Tsv $(200 \mu \mathrm{g} / \mathrm{kg}$ ). A half of the animals in each group were subjected to CLP $6 \mathrm{~h}$ later (CLP and CLP + Tsv). The bronchoalveolar lavage fluid was collected $18 \mathrm{~h}$ after the Tsv injection (i.e. $12 \mathrm{~h}$ after the CLP). The cytokines levels were performed in the BAL using CBA assay.

\begin{tabular}{lcccc}
\hline & PBS & Tsv & CLP & CLP + Tsv \\
\hline MCP-1 & $55.0 \pm 5.8$ & $58.0 \pm 13.0$ & $78.0 \pm 10.9^{\#}$ & $92.0 \pm 37.7^{*}$ \\
IL-12 & $33.9 \pm 6.8$ & $37.1 \pm 12.8$ & $44.3 \pm 9.3$ & $40.0 \pm 12.9$ \\
IL-6 & $16.5 \pm 9.4$ & $13.0 \pm 0.9$ & $177.4 \pm 13.7^{\#}$ & $380.3 \pm 341.4^{*}$ \\
TNF- $\alpha$ & $52.2 \pm 40.8$ & $50.0 \pm 15.6$ & $45.4 \pm 31.5$ & $66.7 \pm 44.1$ \\
IFN- $\gamma$ & $3.7 \pm 1.2$ & $4.3 \pm 1.4$ & $350.0 \pm 0.9$ & $3.9 \pm 110.5$ \\
IL-10 & $213.6 \pm 109.7$ & $287.3 \pm 141.9$ & & $283.6 \pm 98.2$ \\
\hline
\end{tabular}

a mean \pm S.D. of 5 animals per group $(\mathrm{pg} / \mathrm{mL})$.

${ }^{\#} p<0.05$ when compared to PBS group.

${ }^{*} p<0.05$ when compared to Tsv group. 


\section{Table 4}

Total and differential cell counting in the peritoneal cavity from non-septic or septic mice treated with Tityus serrulatus venom (Tsv). Mice were injected subcutaneously with PBS or Tsv $(200 \mu \mathrm{g} / \mathrm{kg})$. A half of the animals in each group were subjected to CLP 6 h later (CLP and CLP + Tsv). The peritoneal cells were collected and counted $18 \mathrm{~h}$ after the Tsv injection (i.e. $12 \mathrm{~h}$ after the CLP).

\begin{tabular}{lllll}
\hline & PBS & Tsv & CLP & CLP + TsV \\
\hline Total & $1.2 \pm 0.2^{\mathrm{a}}$ & $1.3 \pm 0.2$ & $4.6 \pm 0.8$ & $4.2 \pm 0.7$ \\
Macrophage & $1.1 \pm 0.1$ & $1.1 \pm 0.2$ & $0.5 \pm 0.2$ & $1.7 \pm 1.0^{*}$ \\
Neutrophils & $0.0 \pm 0.0$ & $0.0 \pm 0.0$ & $3.9 \pm 0.9$ & $2.3 \pm 1.7^{*}$ \\
Lymphocytes & $0.1 \pm 0.1$ & $0.1 \pm 0.1$ & $0.3 \pm 0.1$ & $0.2 \pm 0.1$ \\
Mast cell & $0.0 \pm 0.0$ & $0.1 \pm 0.1$ & $0.0 \pm 0.0$ & $0.0 \pm 0.0$ \\
\hline
\end{tabular}

${ }^{*} p<0.05$ when compared to the CLP group.

a means \pm S.D. of 5 animals per group $\left(\times 10^{6} / \mathrm{mL}\right)$.

experiments, the effect of Tsv on peritoneal and/or blood Gram-negative enterobacteria that extravasated after CLP could be one feature that improves sepsis outcomes in mice. The in vivo bactericidal activity of scorpion venom was demonstrated in a recent study (Cao et al., 2012).

In addition to the possible bactericidal effects of scorpion venoms, indirect activity via the production of microbicidal products by leukocytes could also be associated with the survival index. In a CLP model of sepsis, the first leukocytes that contact extravasated bacteria are macrophages and mast cells in the peritoneal cavity, which is the initial locus of the inflammatory reaction during CLPinduced sepsis.

Here, we demonstrated that peritoneal cells from animals pretreated with Tsv produced more $\mathrm{H}_{2} \mathrm{O}_{2}$ ex vivo than those from mice submitted only to CLP; even more $\mathrm{H}_{2} \mathrm{O}_{2}$ was produced when such cells were co-stimulated with phorbol myristate acetate (PMA). Macrophages and neutrophils are involved $\mathrm{H}_{2} \mathrm{O}_{2}$ production, and both of these cell types were present in the peritoneal cavities in the CLP and Tsv-pretreated groups. In the CLP group, the number of neutrophils was higher than the number of macrophages. In the Tsv-pretreated group, the number of macrophages was increased and the number of neutrophils was decreased compared to the CLP group. A similar pattern in

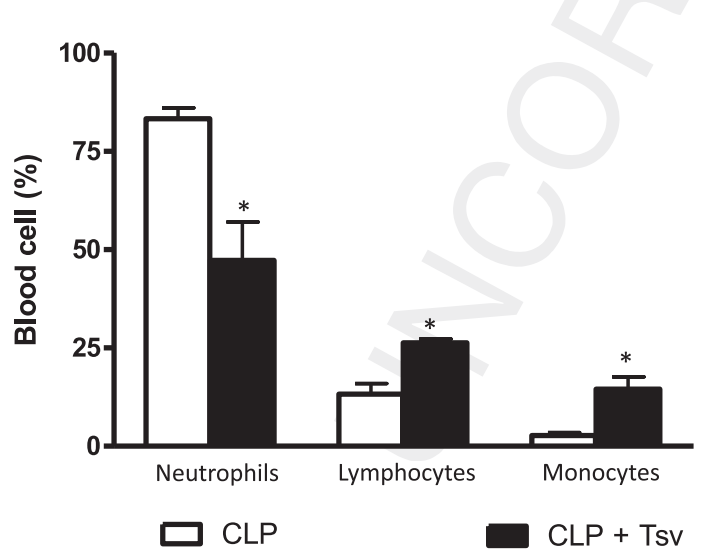

Fig. 2. Differential cell counts in the blood of septic mice pretreated with Tityus serrulatus venom (Tsv). The mice were injected subcutaneously with PBS (CLP) or Tsv $(200 \mu \mathrm{g} / \mathrm{kg})$ and submitted to CLP 6 h later. Blood samples were collected $12 \mathrm{~h}$ after CLP to prepare the slides. The results are expressed as the means \pm SD of 5 animals per group. ${ }^{*} p<0.05$ compared to CLP.
Table 5

Evaluation of prophylactic treatment with Tsv on the lymphoid organs from non-septic or septic mice treated with Tityus serrulatus venom (Tsv) Mice were injected subcutaneously with PBS or Tsv $(200 \mu \mathrm{g} / \mathrm{kg})$. A half of the animals in each group were subjected to CLP $6 \mathrm{~h}$ later (CLP and CLP + Tsv). The lymphoid organs were collected and counted $18 \mathrm{~h}$ after the Tsv injection (i.e. $12 \mathrm{~h}$ after the CLP)

\begin{tabular}{lllrl}
\hline & PBS & \multicolumn{1}{l}{ Tsv } & \multicolumn{1}{l}{ CLP } & CLP + Tsv \\
\hline Bone marrow & $5.7 \pm 0.5^{\mathrm{a}}$ & $5.2 \pm 1.4$ & $9.0 \pm 0.4$ & $6.0 \pm 0.3^{*}$ \\
Lymph node & $4.4 \pm 0.4$ & $2.7 \pm 0.5^{\#}$ & $11.0 \pm 1.6$ & $6.0 \pm 0.8^{*}$ \\
Spleen & $5.6 \pm 1.4$ & $6.5 \pm 0.8$ & $14.0 \pm 1.6$ & $8.0 \pm 0.5^{*}$ \\
\hline
\end{tabular}

\# $p<0.05$ when compared to PBS group.

${ }^{*} p<0.05$ when compared to CLP group.

a The data are expressed as means \pm SD of 5 animals per group $(n=5$ ) group).

the number of monocytes and neutrophils was observed in the blood; at the same time, a reduction in the number of cells was observed in the lymphoid organs. Previously, we demonstrated that $6 \mathrm{~h}$ after the subcutaneous administration of Tsv, the number of neutrophils was increased in the blood; this time corresponded to the moment of sepsis induction in this study. However, the neutrophil number in the peritoneal cavity was not changed by subcutaneous Tsv administration (Fialho et al., 2011). Taken together, the data described above allow us to speculate that in the Tsvpretreated animals, there was a mobilization of immune cells from the lymphoid organs to the blood and subsequently towards the peritoneal cavity, which is the focus of inflammation after CLP. In the peritoneal cavity, the phagocytes stimulated by Tsv interacted with bacteria that extravasated from the cecum. The subsequent high production of $\mathrm{H}_{2} \mathrm{O}_{2}$ gives phagocytes an advantage when killing bacteria. In fact, phagocytosis and the production of $\mathrm{H}_{2} \mathrm{O}_{2}$ and nitric oxide (NO) were observed in vitro in Tsvstimulated macrophages (Petricevich, 2002; Petricevich et al., 2008). The augmented number of macrophages in the peritoneal cavity of Tsv-pretreated mice may be related

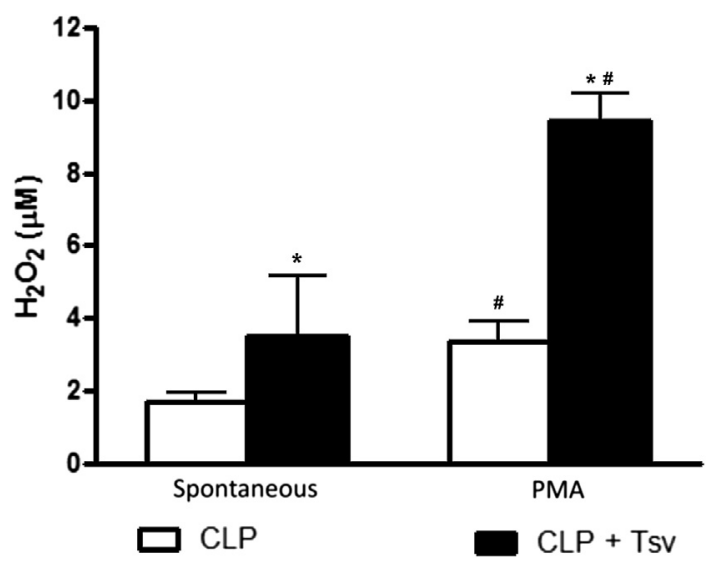

Fig. 3. Ex vivo hydrogen peroxide release by peritoneal cells from septic mice treated with Tityus serrulatus venom (Tsv). The mice were injected subcutaneously with PBS (CLP) or Tsv $(200 \mu \mathrm{g} / \mathrm{kg})$ and submitted to CLP $6 \mathrm{~h}$ later. The peritoneal cells were collected $12 \mathrm{~h}$ after CLP and were cultured in the presence or absence of PMA to quantify $\mathrm{H}_{2} \mathrm{O}_{2}$ secretion. The results are expressed as the means \pm SD of 5 animals per group. ${ }^{*} p<0.05$ compared to CLP, $\# p<0.05$ compared to spontaneous release. 
to the activation of neutrophils and resident macrophages because these cells may produce MCP-1 (Speyer et al., 2004; Henderson et al., 2003).

Neutrophils are important effectors in the control of CLP-induced sepsis, and early neutrophil depletion prior to CLP is associated with high bacteremia and rapid death in animals (Hoesel et al., 2005). The outcome of sepsis is correlated with neutrophil migration to the peritoneal cavity, and the presence of few neutrophils in the focus of the inflammatory response is associated with a worse prognosis (Alves-Filho et al., 2005, 2010). Considering the involvement of immune cells, our results suggest that after Tsv pretreatment, more neutrophils in the blood were ready to migrate towards the peritoneal cavity soon after the trigger of sepsis by CLP; as a result, extravasated bacteria were killed by neutrophils and macrophages, which were both activated by Tsv, thus avoiding the establishment of fatal sepsis.

\section{Uncited reference}

Amitai, 1998; Rittirsh et al., 2008.

\section{Acknowledgments}

We thank the Brazilian funding agencies CAPES, CNPq, FAPESP, and FAPEMA for financial support. We also thanks to Thiare Fortes, Aramys Reis and Anne Karine Assunção for technical assistance.

\section{Conflict of interest statement}

The authors declare that there are no conflicts of interest.

\section{References}

Adi-Bessalem, S., Hammoudi-Triki, D., Laraba-Djebari, F., 2008. Pathophysiological effects of Androctonus australis hector scorpion venom: tissue damages and inflammatory response. Exp. Toxicol. Pathol. 60, 373-380.

Ahmed, U., Mujaddad-ur-Rehman, M., Khalid, N., Fawad, S.A., Anees, F., 2012. Antibacterial activity of the venom of Heterometrus xanthopus. Indian J. Pharmacol. 44, 509-511.

Alves-Filho, J.C., Benjamim, C., Tavares-Murta, B.M., Cunha, F.Q., 2005. Failure of neutrophil migration toward infectious focus in severe sepsis: a critical event for the outcome of this syndrome. Mem. Inst. Oswaldo Cruz 100 (Suppl. I), 223-226.

Alves-Filho, J.C., Spiller, F., Cunha, F.Q., 2010. Neutrophil paralysis in sepsis. Shock 34 (Suppl. 1), 15-21.

Amitai, Y., 1998. Clinical manifestations and managements of scorpion envenomation. Public Health Rev. 26, 257-263.

Angus, D.C., Linde-Zwirble, W.T., Lidicker, J., Clermont, G., Carcillo, J., Pinsky, M.R., 2001. Epidemiology of severe sepsis in the United States: analysis of incidence, outcome, and associated costs of care. Crit. Care Med. 29, 1303-1310.

Benjamim, C.F., Ferreira, S.H., Cunha, F.Q., 2000. Role of nitric oxide in the failure of neutrophil migration in sepsis. J. Infect. Dis. 182, 214-223.

Borges, A., Op den Camp, H.J.M., De Sanctis, J.B., 2011. Specific activation of human neutrophils by scorpion venom: a flow cytometry assessment. Toxicol. In vitro 25, 358-367.

Cao, L., Dai, C., Li, Z., Fan, Z., Song, Y., Wu, Y., Cao, Z., Li, W., 2012. Antibacterial activity and mechanism of a scorpion venom peptide derivative in vitro and in vivo. PLoS One 7,1-11.

Cavaillon, J.M., Adib-Conquy, M., Fitting, C., Adrie, C., Payen, D., 2003. Cytokine cascade in sepsis. Scand. J. Infect. Dis. 35, 535-544.

Ciscotto, P., Machado de Avila, R.A., Coelho, E.A.F., Oliveira, J., Diniz, C.G., Farías, L.M., Carvalho, M.A.R., Maria, W.S., Sanchez, E.F., Borges, A.,
Chávez-Olórtegui, C., 2009. Antigenic, microbicidal and antiparasitic properties of an L-amino acid oxidase isolated from Bothrops jararaca snake venom. Toxicon 53, 330-341.

Conde, R., Zamudio, F.Z., Rodríguez, M.H., Possani, L.D., 2000. Scorpine, an anti-malaria and anti-bacterial agent purified from scorpion venom. FEBS Lett. 471, 165-168.

Corzo, G., Escoubas, P., Villegas, E., Barnham, K.J., He, W., Norton, R.S., 2001. Characterization of unique amphipathic antimicrobial peptides from venom of the scorpion Pandinus imperator. Biochem. J. 359, 35-45.

Díaz, P., D'Suze, G., Salazar, V., Sevcik, C., Shannon, J.D., Sherman, N.E., Fox, J.W., 2009. Antibacterial activity of six novel peptides from Tityus discrepans scorpion venom. A fluorescent probe study of microbial membrane $\mathrm{Na}^{+}$permeability changes. Toxicon $54,802-817$.

Fialho, E.M.S., Maciel, M.C.G., Silva, A.C.B., Reis, A.S., Assunção, A.K.M., Fortes, T.S., Silva, L.A., Guerra, R.N.M., Kwasniewski, F.H., Nascimento, F.R.F., 2011. Immune cells recruitment and activation by Tityus serrulatus scorpion venom. Toxicon 58, 480-485.

Frolkis, I., Klein, Y., Locker, C., Adi, N., Dahan, E., Uretzsky, G., Shapira, I., Sorkine, P., 2010. Vipera aspis venom reduces lethality and downregulates tumor necrosis factor- $\alpha$. in a rat model of LPS-induced sepsis. Cytokine 49, 319-324.

Fukuhara, Y.D.M., Reis, M.L., Dellalibera-Joviliano, R., Cunha, F.Q.C., Donadi, E.A., 2003. Increased plasma levels of IL-1b, IL-6, IL-8, IL-10 and TNF-alpha in patients moderately or severely envenomed by Tityus serrulatus scorpion sting. Toxicon 41, 49-55.

Garrido, A.G., Poli de Figueiredo, L.F., Rocha e Silva, M., 2004. Experimental models of sepsis and septic shock: an overview. Acta Cir. Bras. 19, 82-88.

Gérard, C., Bruyns, C., Marchant, A., Abramowicz, D., Vandenabeele, P., Delvaux, A., Fiers, W., Goldman, M., Velu, T., 1993. Interleukin 10 reduces the release of tumor necrosis factor and prevents lethality in experimental endotoxemia. J. Exp. Med. 177, 547-550.

Henderson, R.B., Hobbs, J.A.R., Mathies, M., Hogg, N., 2003. Rapid recruitment of inflammatory monocytes is independent of neutrophil migration. Blood 102, 328-335.

Hoesel, L.M., Neff, T.A., Neff, S.B., Younger, J.G., Olle, E.W., Gao, H., Pianko, M.J., Bernacki, K.D., Sarma, J.V., Ward, P.A., 2005. Harmful and protective roles of neutrophils in sepsis. Shock 24, 40-47.

Maciel, M.C.G., Farias, J.C., Maluf, M.J., Gomes, E.A., Pereira, P.V.S., AragãoFilho, W.C., Frazão, J.B., Costa, G.C., Sousa, S.M., Silva, L.A., Amaral, F.M.M., Russo, M., Guerra, R.N.M., Nascimento, F.R., 2008. Syzygium jambolanum treatment improves survival in lethal sepsis induced in mice. BMC Complement. Altern. Med. 8, 57-64.

Moerman, L., Bosteels, S., Noppe, W., Willems, J., Clynen, E., Schoofs, L., Thevissen, K., Tytgat, J., Van Eldere, J., Van der Walt, J., Verdonck, F., 2002. Antibacterial and antifungal properties of a-helical, cationic peptides in the venom of scorpions from southern Africa. Eur. J. Biochem. 269, 4799-4810.

Moore, K.W., de Waal Malefyt, R., Coffman, R.L., O'Garra, A., 2001. Interleukin-10 and the interleukin-10 receptor. Annu. Rev. Immunol. 19, 683-765.

Pessini, A.C., Souzam, A.M., Faccioli, L.H., Gregório, O.Z.M., Arantes, E.C., 2003. Time course of acute-phase response induced by Tityus serrulatus venom and TsTX-I in mice. Int. Immunopharmacol. 3, 765-774.

Petricevich, V.L., 2002. Effect of Tityus serrulatus venom on cytokine production and the activity of murine macrophages. Med. Inflamm. 11, 23-31.

Petricevich, V.L., 2006. Balance between pro- and anti-inflammatory cytokines in mice treated with Centruroides noxius scorpion venom. Med. Inflamm. 6, 1-11.

Petricevich, V.L., 2010. Scorpion venom and the inflammatory response. Med. Inflamm. 2010, 1-16.

Petricevich, V.L., Reynaud, E., Cruz, A.H., Possani, L.D., 2008. Macrophage activation, phagocytosis and intracellular calcium oscillations induced by scorpion toxins from Tityus serrulatus. Clin. Exp. Immunol. 154, 415-423.

Petricevichi, V.L., Peña, C.F., 2002. The dynamics of cytokine d nitric oxide secretion in mice injected with Tityus serrulatus scorpion venom. Med. Inflamm. 11, 173-180.

Pick, E., Keisari, Y., 1980. A simple colorimetric method for the measurement of hydrogen peroxide produced by cells in culture. J. Immunol. Methods 38, 161-170.

Pick, E., Mizel, D., 1981. Rapid microassays for the measurement of superoxide and hydrogen peroxide production by macrophages in culture using an automatic enzyme immunoassay reader. J. Immunol. Methods 46, 211-226.

Rittirsh, D., Flierl, M.A., Ward, P.A., 2008. Harmful molecular mechanisms in sepsis. Nat. Rev. Imunol. 8, 776-787. 
Rocco, P.R.M., Pelosi, P., 2008. Pulmonary and extrapulmonary acute respiratory distress syndrome: myth or reality? Curr. Opin. Crit. Care 14, 50-55.

Severino, D.N., Pereira, R.L., Knysak, I., Cândido, D.M., Kwasniewski, F.H. 2009. Edematogenic activity of scorpion venoms from the buthidae family and the role of platelet-activating factor and nitric oxide in paw edema induced by Tityus venoms. Inflammation 32, 57-64.

Silva, E., Pedro, M.A., Sogayar, A.C.B., Mohovic, T., Silva, C.L.O., Janiszewski, M., Cal, R.G.R., Sousa, E.F., Abe, T.P., Andrade, J., Matos, J.D., Rezende, E., Assunção, M., Avezum, A., Rocha, P.C.S. Matos, G.F.J., Bento, A.M., Corrêa, A.D., Vieira, P.C.B., Knobel, E., 2004 Brazilian sepsis Epidemiological study (BASES study). Crit. Care 8 , $251-260$.

Speyer, C.L., Gao, H., Rancilio, N.J., Neff, T.A., Huffnagle, G.B., Sarma, J.V., Ward, P.A., 2004. Novel chemokine responsiveness and mobilization of neutrophils during sepsis. Am. J. Pathol. 165, 2187-2196.
Van Der Poll, T., Marchant, A., Buurman, W.A., Berman, L., Keogh, C.V. Lazarus, D.D., Nguyen, L., Goldman, M., Moldawer, L.L., Lowry, S.F., 1995. Endogenous IL-10 protects mice from death during septic peritonitis. J. Immunol. 155, 5397-5401.

Wang, H., Li, W., Li, J., Rendon-Mitchell, B., Ochani, M., Ashok, M., Yang, L., Yang, H., Tracey, K.J., Wang, P., Sama, A.E., 2006. The aqueous extract of a popular herbal nutrient supplement, Angelica sinensis, protects mice against lethal endotoxemia and sepsis. J. Nutr. 136, 360-365.

Yang, J., Dai, Y., Xia, Y.F., Huang, W.Z., Wang, Z.T., 2009. Alpinia katsumadai Hayata prevents mouse sepsis induced by cecal ligation and puncture through promoting bacterial clearance and downregulating systemic inflammation. Phytother. Res. 23, 267-273.

Zoccal, K.F., Bitencourt, C.S., Secatto, A.S., Sorgi, C.A., Bordon, K.C.F. Sampaio, S.V., Arantes, E.C., Faccioli, L.H., 2011. Tityus serrulatus venom and toxins Ts1, Ts2 and Ts6 induce macrophage. activation and production of immune mediators. Toxicon 57, 1101-1108. 